\title{
PENGGUNAAN THEORY OF PLANNED BEHAVIOR DALAM MENGANALISIS FAKTOR-FAKTOR YANG MEMENGARUHI FOOD WASTE BEHAVIOR PADA DOSEN
}

\author{
Dimas Teguh Prasetyo ${ }^{1^{*}}$, Ratna Djuwita ${ }^{1}$ \\ ${ }^{1}$ Fakultas Psikologi, Universitas Indonesia, Depok 16424, Indonesia \\ *)E-mail: dimasteguhprasetyo2394@gmail.com
}

\begin{abstract}
Abstrak
Salah satu lingkungan yang turut berkontribusi menghasilkan sampah makanan ialah lingkungan institusi perguruan tinggi. Studi ini bertujuan menganalisis perilaku membuang makanan pada dosen dan faktor-faktor yang memengaruhinya dengan menggunakan kerangka Theory of Planned Behavior (TPB). Studi 1 dilakukan dengan mewawancari empat dosen yang mengikuti pelatihan dosen. Studi 2 dilakukan untuk menguji faktor yang memengaruhi perilaku membuang makanan dengan kerangka TPB secara kuantitatif. Survei daring dilakukan kepada 99 dosen dari 11 fakultas. Hasil analisis tematik secara kualitatif menemukan bahwa makanan yang terbuang sia-sia dianggap dapat dimanfaatkan kembali menjadi pupuk bagi kampus (behavioral belief). Rekan sejawat menjadi kelompok yang dapat mendorong atau menghambat perilaku membuang makanan dalam pelatihan (normative belief). Para dosen pun sepakat bahwa makanan dapat dibuang jika mengandung gizi yang berlebihan (control belief). Temuan tersebut kemudian dikonfirmasi dengan analisis regresi ganda yang menemukan bahwa hanya atittude dan subjective norm yang mampu memprediksi intensi secara signifikan. Selain itu, Perceived Behavioral Control (PBC) dan intensi secara terpisah mampu memprediksi perilaku membuang makanan secara signifikan. Identifikasi belief-belief sebagai anteseden variabel prediktor dalam kerangka TPB memudahkan peneliti untuk menangkap gambaran perilaku food waste secara spesifik. Hasil studi ini juga dapat menjadi acuan intervensi untuk mengurangi perilaku membuang makanan pada dosen di kegiatan pelatihan.
\end{abstract}

Kata kunci: dosen, perilaku, sampah makanan, Theory of Planned Behavior

\section{Theory of Planned Behavior for Examining Factors Related to Food Waste Behavior among Lecturer}

\begin{abstract}
Higher education institution is one of the institutions that produce food waste continually. This study aims to empirically examine the food waste behavior among the lecturer and explore the factors related to the framework of the Theory of Planned Behavior (TPB). Study 1 was by interviewing four lecturers in lecturer training. Study 2 was conducted to explore the factors related to food waste behavior within the framework of the Theory of Planned Behavior quantitatively. An online survey was held among 99 lecturers from 11 faculties. Thematic analysis qualitatively found that food waste can transform into fertilizer for the campus (behavioral belief). Their colleagues have become a reference group that can motivate them to produce food waste in training (normative referent). They also argue that more unhealthy food has a higher consequence to waste. Multiple regression analysis found that only attitude and subjective norms predict significantly toward the intention. However, perceived behavioral control and intention separately predict food waste behavior significantly. The identification of salient beliefs was very helpful to capture food waste behavior specifically. This study also useful for preparing the intervention study to prevent food waste behavior among lecturers on lecturer training.
\end{abstract}

Keywords: behavior, lecturer, food waste, Theory of Planned Behavior

\section{PENDAHULUAN}

Sampah makanan kini tengah menjadi perhatian global. Badan Pangan Dunia mengeluarkan data bahwa sekitar 1,6 giga ton makanan terbuang sia-sia setiap tahunnya secara global (FAO, 2013). Sebagai negara dengan penduduk terbesar keempat di dunia, Indonesia merupakan negara kedua yang menghasilkan sampah makanan terbesar di dunia (EIU, 2018). Masalah sampah makanan telah masuk pada poin ke-12 dalam Sustainability Development Goals yang terkait dengan upaya dunia dalam menekan zero food 
hunger dan responsible consumption and production (Guinee, 2018). Data-data tersebut menunjukan bahwa masalah sampah makanan sudah saatnya menjadi tanggung jawab seluruh warga dunia, termasuk Indonesia.

Makanan yang terbuang dan menjadi sampah menimbulkan kerugian pada beberapa aspek kehidupan manusia. Makanan yang terbuang akan berimplikasi terhadap sumber daya yang digunakan dalam proses produksi makanan seperti listrik, bahan bakar, dan tenaga kerja (Kariyasa \& Suryana, 2016). Makanan yang terbuang dan menumpuk di landfill akan menghasilkan gas metana 21 kali lebih berbahaya dari karbondioksida (FAO, 2011). Zat organik dalam sampah makanan yang tidak diolah juga dapat menyebabkan pencemaran lingkungan (Fadhilah \& Yudihanto, 2013). Bahkan, aktivitas pengomposan sampah makanan dapat menyumbang emisi gas rumah kaca dalam skala kecil (Kiswadayani, Susanawati, \& Wirosoedarmo, 2016). Sampah makanan juga sering dikaitkan dengan kondisi penduduk miskin di Indonesia. Data Badan Pusat Statistik menunjukan bahwa penduduk yang masuk dalam garis kemiskinan berkisar di atas 10 persen dari populasi penduduk Indonesia (BPS, 2018). Fakta-fakta tersebut semakin meyakinkan bahwa sampah makanan berkaitan erat dengan aspek-aspek vital dalam kehidupan manusia di Indonesia.

Studi tentang sampah makanan memang telah dilakukan oleh beberapa peneliti sebelumnya. Fenomena munculnya sampah makanan telah banyak dijelaskan dalam konstruk food waste behaviour. Aschemann-Witzel, De Hooge, Amani, Bech-Larsen, dan Oostindjer (2015) mendefinisikan perilaku food waste sebagai perilaku menghasilkan sisa makanan sehingga berpotensi menjadi sampah atau limbah makanan. Studi juga menemukan bahwa food waste behavior dapat dipengaruhi oleh faktor emosi dan afeksi (Egolf, Siegist, \& Hartmann, 2018; Porpino, Wansink, \& Parente, 2016). Selain itu, terdapat juga faktor eksternal yang turut memengaruhi perilaku food waste seperti budaya (Bozzola, Da Palu, \& Giorgi, 2017) dan norma sosial (Dorn \& Stockli, 2018). Meski demikian, faktor eksternal maupun internal akan secara dinamis saling terkait dengan perilaku food waste seseorang.

Salah satu institusi yang turut berkontribusi menghasilkan sampah makanan ialah perguruan tinggi. Studi sebelumnya menilai bahwa perguruan tinggi perlu mendapat perhatian pada masalah sampah makanan (Painter, Thondhlana, \& Kua, 2016; Whitehair,
Shanklin, \& Brannon, 2013). Perguruan tinggi juga perlu menjadi tempat berkembangnya ilmu pengetahuan yang berlandaskan pembangunan berkelanjutan (Lozano, Lozano, Mulder, Huisingh, \& Waas, 2013). Namun, fakta tersebut berkebalikan dengan kondisi perguruan tinggi $X Y Z$. Lokasi yang dipilih dalam penelitian ini merupakan perguruan tinggi yang masuk dalam peringkat 10 besar green campus di Indonesia (http://greenmetric.ui.ac.id, 2019), nyatanya belum mampu menekan produksi sampah makanan. Data penimbangan sampah organik di perguruan tinggi $X Y Z$ sepanjang bulan September 2018 diketahui sebanyak 9,1 ton (Mulya, 2018). Data tersebut cukup menguatkan bahwa perguruan tinggi turut memiliki tanggung jawab terhadap masalah sampah makanan yang dihasilkan oleh para warganya.

Salah satu kegiatan yang berpotensi menghasilkan sampah makanan secara rutin di perguruan tinggi $\mathrm{XYZ}$ adalah kegiatan pelatihan dosen. Pelatihan dosen merupakan kegiatan rutin yang dilakukan hampir setiap minggu di perguruan tinggi $X Y Z$. Hasil penimbangan sampah makanan selama 2 minggu menunjukan bahwa pelatihan dosen menghasilkan rata-rata sebanyak 2,5 kilogram sampah makanan setiap harinya (Tiwi, 2018). Jika hasil ini di ekstrapolasi selama setahun, sampah makanan yang dihasilkan sebesar 60 kilogram. Jumlah tersebut relatif besar karena kemampuan kampus dalam mengolah sampah makanan menjadi pupuk memerlukan waktu setidaknya 90 hari untuk setiap minggunya. Keterbatasan lahan dan sumber daya dalam mengelola sampah makanan memberi dampak pada antrian sampah makanan yang akan diolah. Semakin besarnya jumlah sampah makanan yang terjadi di kampus maka potensi penumpukan sampah makanan dalam pengelolaan kompos akan semakin tinggi. Sebuah upaya pencegahan diperlukan dalam mengurangi terjadinya sampah makanan. Pencegahan dapat dilakukan mulai dari mengetahui perilaku food waste itu sendiri dan faktor-faktor yang memengaruhinya terutama pada para dosen sebagai peserta pelatihan rutin di kampus.

Salah satu kerangka berpikir yang telah banyak digunakan dalam setting perilaku prolingkungan adalah Theory of Planned Behavior (TPB). TPB dapat menjelaskan perilaku konsumsi makanan salah satunya yakni food waste behavior (Ajzen, 2015). Teori ini menjelaskan bahwa atittude, subjective norms, dan Perceived Behavioral Control (PBC) mampu memprediksi intensi sebagai cerminan dari food waste 
behavior itu sendiri. Teori ini kemudian didukung oleh temuan-temuan studi setelahnya dalam konteks perilaku prolingkungan (Graham-Rowe, Jessop, \& Sparks, 2015; Mak, Iris, Tsang, Hsu, \& Poon, 2018; MondéjarJiménez, Ferrari, Secondi, \& Principato, 2016; Russell, Young, Unsworth, \& Robinson, 2017).

Tiga variabel antesenden kerangka TPB yakni atittude, subjective norms, dan PBC turut dipengaruhi oleh adanya belief. Ajzen (2005) menjelaskan bahwa terdapat behavioral belief yang menghasilkan perilaku menguntungkan atau merugikan terhadap suatu perilaku (attitude towards behavior). Normative belief menggambarkan individu atau kelompok yang dapat menghambat atau mendukung sebuah perilaku yang kemudian menghasilkan subjective norms. Sementara itu, control belief berisi faktor-faktor lain yang memfasilitasi atau menghambat timbulnya sebuah perilaku yang dapat menghasilkan PBC. Pengujian belief dalam kerangka TPB juga dilakukan dalam studi-studi sebelumnya. Studi oleh Agar (2018) berusaha menemukan terlebih dahulu belief yang salient dalam konteks perilaku wanita terkait mothering dan karir. Pendekatan kualitatif juga digunakan untuk mengetahui belief yang menjadi kunci pada konteks perilaku konsumen (Carr, Shin, Severt, \& Lewis, 2017; Shin, Im, \& Severt, 2020). Identifikasi belief yang spesifik dan salient faktanya turut memudahkan peneliti yang menggunakan kerangka TPB dalam mengkontruk tiga variabel antesenden yang akan diuji yakni atittude, subjective norms, dan PBC.

Penggunaan TPB sering digunakan dalam menjelaskan perilaku prolingkungan di Indonesia. Beberapa studi menggunakan TPB untuk menjelaskan perilaku memilah sampah (Afifah \& Djuwita, 2019), membeli tumbler (Mamahit, Kalangi, \& Pandowo, 2019), pembelian produk green fashion (Sofiani \& Saefuloh, 2019) dan penggunaan tas belanja (Volva \& Djamaludin, 2018). Studi perilaku food waste dengan menggunakan TPB sebenarnya pernah dilakukan oleh Prasetyo (2019). Namun, studi tersebut terbatas hanya menganalisis belief secara kualitatif. Selain itu, studi perilaku prolingkungan dengan menggunakan TPB yang dilakukan di perguruan tinggi baru melibatkan partisipan mahasiswa (Mamahit et al., 2019) dan pedagang kantin (Afifah \& Djuwita, 2019). Hal tersebut tidak sejalan dengan studi oleh Lozano et al. (2013) yang menyatakan bahwa semua sivitas akademika memiliki kewajiban untuk mewujudkan pembangunan berkelanjutan di perguruan tinggi, termasuk dosen. Dosen merupakan sivitas akademika yang sering memiliki peran lebih dari pengajar. Dosen sering terlibat sebagai pengambil keputusan mulai di tingkat program studi hingga perguruan tinggi. Oleh karenanya, studi ini bertujuan untuk menganalisis food waste behavior pada dosen dan faktor-faktor yang memengaruhinya. Implikasi studi ini dapat menjadi usulan kebijakan dalam program intervensi pencegahan food waste behavior di perguruan tinggi.

\section{METODE}

\section{Studi 1}

Studi ini menggunakan pendekatan kualitatif dengan metode studi kasus. Peneliti ingin mengeksplorasi kasus yang detail, informasi mendalam pada batasan konteks tertentu serta melaporkan hasil secara deskriptif dalam tema yang sesuai dengan kasus (Cresswell, 2007; Willig, 2008). Fokus Studi 1 berkaitan dengan menganalisis belief dosen terkait food waste behavior. Oleh karena itu, peneliti melakukan wawancara terhadap dosen yang mengikuti pelatihan di perguruan tinggi $X Y Z$. Peneliti menggunakan teknik accidental sampling untuk menentukan informan.

Peneliti pertama kali mengirimkan surat izin penelitian kepada Direktur Sumber Daya dan Pembelajaran perguruan tinggi $X Y Z$. Selanjutnya, peneliti menghubungi koordinator pelatihan dosen untuk keperluan pengambilan data di lapangan. Proses wawancara selalu diawali dengan pemberian informed consent untuk memastikan kesediaan informan. Peneliti hanya mewawancarai partisipan ketika jam makan siang (antara 12.00 - 13.00 WIB). Wawancara dilaksanakan di ruang tunggu Pusat Pelatihan perguruan tinggi $X Y Z$. Peneliti memberikan cinderamata kepada informan sebagai ucapan terima kasih.

Peneliti menggunakan kerangka TPB (Fishbein \& Ajzen, 2010) untuk merancang pertanyaan dalam wawancara. Tiga belief yang digali dalam wawancara yakni behavioral belief, normative belief, dan control belief. Ketiga faktor tersebut dinilai mampu membantu peneliti dalam membangun variabel antensenden dalam TPB. Behavioral belief didefinisikan sebagai keyakinan tentang konsekuensi yang akan terjadi dari sebuah perilaku (Fishbein \& Ajzen, 2010). Variabel ini hanya memiliki satu dimensi yakni behavioral belief itu sendiri dan terdiri atas tiga pertanyaan. Variabel ini termanifestasi dalam bentuk pertanyaan seperti "apa saja keuntungan atau hambatan yang Anda lihat 
dari perilaku membuang makanan?". Jawaban dari pertanyaan ini dibuat secara terbuka.

Variabel kedua yang digunakan yakni normative belief. Definisi normative belief yakni keyakinan tentang ekspektasi normatif yang dilakukan orang lain (Fishbein \& Ajzen, 2010). Variabel ini hanya memiliki satu dimensi yakni normative belief itu sendiri dan terdiri atas 2 pertanyaan. Contoh pertanyaan dari normative belief adalah "coba sebutkan individu atau kelompok yang Anda pikir dapat mendorong atau menghambat seseorang membuang makanan?". Jawaban dari pertanyaan ini dibuat secara terbuka.

Variabel ketiga yang digunakan yakni control belief. Control belief memiliki arti keyakinan tentang faktor apa saja yang kemungkinan dapat mendorong atau menghambat sebuah perilaku terjadi (Fishbein \& Ajzen, 2010). Variabel ini hanya memiliki satu dimensi yakni normative belief itu sendiri dan terdiri atas 2 pertanyaan. Control belief dioperasionalisasikan dalam pertanyaan seperti "coba Anda sebutkan faktor apa saja yang dapat mendorong atau menghambat anda dalam membuang makanan?". Jawaban dari pertanyaan ini dibuat secara terbuka.

Hasil rekaman wawancara kemudian dibuat verbatim. Panjang verbatim setiap orang berkisar antara 114 hingga 230 kata $(M=167$ kata, $S D=48,07$ ). Kata dalam verbatim diolah dengan proses koding, mulai dari pengumpulan hasil pengambilan data, membuat segmentasi kategori hingga memberi label pada kategorikategori yang ada (Cresswell, 2007). Data wawancara dosen yang sudah dikoding, selanjutnya diserahkan kepada expert di bidang TPB. Hal tersebut dilakukan untuk memastikan koding yang dilakukan peneliti sudah tepat. Semua nama informan dalam wawancara menggunakan nama inisial.

\section{Studi 2}

Studi 2 menggunakan pendekatan kuantitatif korelasional untuk menjawab hipotesis. Hipotesis utama dalam studi ini yakni sikap, norma subjektif, dan PBC secara serentak memengaruhi secara signifikan intensi $(\mathrm{H} 1)$, PBC memengaruhi secara signifikan food waste behavior $(\mathrm{H} 2)$, dan intensi memengaruhi secara signifikan food waste behavior (H3). Semua partisipan telah mengisi kesediaannya melalui lembar informed consent di bagian awal kuesioner. Data yang telah terkumpul kemudian dianalisis secara deskriptif dan uji regresi ganda menggunakan aplikasi IBM SPSS versi
24. Studi kedua juga dilaksanakan di perguruan tinggi $X Y Z$.

Sebuah pilot study dilakukan untuk menyusun kuesioner yang akan digunakan sebagai pengumpulan data dalam Studi 2. Kuesioner awal diberikan kepada enam dosen untuk uji keterbacaan. Hasil uji keterbacaan menghasilkan 16 pernyataan dari lima variabel. Kuesioner diberikan dalam bentuk online untuk efisiensi waktu. Pilot study akhirnya menghasilkan 14 pernyataan valid dari lima variabel.

Kuesioner ini diformulasikan menggunakan Theory of Planned Behavior (Fishbein \& Ajzen, 2010). Kuesioner terdiri dari empat bagian yakni informed consent, data demografi partisipan, pertanyaan utama, dan lembar debriefing. Kuesioner ditulis dalam bahasa Indonesia. Peneliti sengaja memberikan judul kuesioner ini dengan penelitian perilaku makan untuk mengurangi bias pada respon pertama partisipan. Peneliti menuliskan tujuan utama penelitian dalam lembar debriefing untuk kepentingan etis studi.

Atittude didefinisikan sebagai faktor dalam diri seseorang yang dipelajari untuk memberikan respon positif atau negatif pada penilaian perilaku membuang makanan (Ajzen, 2015). Variabel ini merupakan uni-dimensional yang terdiri atas empat pernyataan (2 favorable items dan 2 unfavorable items).Contoh pernyataan dalam variabel ini seperti "saya tidak memikirkan adanya pemborosan sumber daya alam saat membuang makanan. Pernyataan memiliki jawaban dengan skala Likert dari rentang skala 1 hingga $6 \quad(1=$ sangat tidak setuju, $6=$ sangat setuju).

Subjective norm didefinisikan sebagai persepsi seseorang tentang pemikiran orang lain yang akan mendukung atau tidak mendukungnya dalam membuang makanan (Ajzen, 2015). Variabel ini merupakan uni-dimensional yang terdiri atas 3 pernyataan ( 1 favorable items dan 2 unfavorable items). Contoh pernyataan dalam variabel ini seperti "teman sejawat saya menganggap bahwa membuang makanan adalah hal yang wajar". Pernyataan memiliki jawaban dengan skala Likert dari rentang skala 1 hingga 6 ( $1=$ sangat tidak setuju, $6=$ sangat setuju).

Perceived Behavioral Control (PBC) didefinisikan sebagai persepsi kemudahan atau kesulitan dalam membuang makanan (Ajzen, 2015). Variabel ini merupakan uni-dimensional yang terdiri atas 4 pernyataan (1 favorable 
items dan 3 unfavorable items). Contoh pernyataan pada variabel ini seperti "agar tetap dapat menghabiskan makanan, saya berusaha mengetahui kandungan gizinya". Pernyataan memiliki jawaban dengan skala Likert dari rentang skala 1 hingga 6 (1=sangat tidak setuju, $6=$ sangat setuju).

Intention didefinisikan sebagai anteseden perilaku membuang makanan yang segera (Ajzen, 2015). Variabel ini merupakan unidimensional yang terdiri atas 2 pernyataan (2 unfavorable items). Contoh pernyataan pada variabel ini seperti "saya tidak akan membuang makanan di kemudian hari". Pernyataan memiliki jawaban dengan skala Likert dari rentang skala 1 hingga 6 (1=sangat tidak setuju, $6=$ sangat setuju).

Food waste behavior didefinisikan sebagai perilaku membuang makanan yang masih layak makan sehingga menimbulkan sampah makanan (Ajzen, 2015). Variabel ini merupakan uni-dimensional yang terdiri atas 2 pernyataan (2 unfavorable items). Contoh pernyataan pada variabel ini seperti"saya selalu membawa pulang makanan yang tidak habis". Pernyataan memiliki jawaban dengan skala Likert dari rentang skala 1 hingga 6 (1=sangat tidak setuju, $6=$ sangat setuju).

Uji validitas dan reliabilitas alat ukur dilakukan sebelum melakukan pengambilan data. Alat ukur diujikan kepada 31 partisipan dosen dengan rerata usia 45,23 tahun $(S D=16,41)$ di lima fakultas perguruan tinggi $X Y Z$. Metode pengujian reliabilitas yang digunakan adalah single trial test karena tes hanya dilakukan sebanyak satu kali kepada partisipan. Perhitungan reliabilitas menggunakan koefisien Cronbach's alpha. Metode ini dinilai efektif dalam mengukur reliabilitas alat ukur yang didasarkan pada respon terhadap semua pernyataan (internal consistency). Uji reliabilitas mengkorelasikan dengan melihat performa individu pada satu pernyataan dengan performa pada keseluruhan pernyataan (total). Hasil menunjukan atittude memiliki $r$ sebesar 0,48 ; subjective norm memiliki $r$ sebesar 0,35; PBC memiliki $r$ sebesar 0,37 ; intention memiliki $r$ sebesar 0,75 ; dan food waste behavior memiliki $r$ sebesar 0,51 .

Kuesioner yang telah diuji validitas dan reliabilitasnya selanjutnya diberikan kepada dosen-dosen perguruan tinggi $\mathrm{XYZ}$ yang memiliki kesamaan karakteristik dengan peserta pelatihan dosen. Peneliti menggunakan teknik accidental sampling dalam studi ini. Total terdapat 99 partisipan yang mengisi kuesioner (usable response rate $=100 \%$ ). Secara statistik, total responden dalam studi ini dinilai telah representatif. Keputusan ini didukung dengan hasil analisis statistik $G^{*}$ Power (Faul, Erdfelder, Lang, \& Buchner, 2007) yang menyatakan bahwa total sampel minimal dalam penelitian ini adalah 65 orang dengan menghasilkan effect size sebesar 0,33 dan power 0,95 (sangat kuat). Survey daring diisi oleh partisipan melalui surel dan chatting messenger application. Peneliti memberikan souvenir kepada partisipan di akhir pengisian kuesioner.

\section{HASIL}

\section{Studi 1}

Karakteristik Dosen. Peneliti melakukan wawancara terhadap empat dosen yang sedang mengikuti pelatihan. 3 dari 4 partisipan didominasi perempuan dan berusia 28-50 tahun $(M=34$ tahun; $S D=10,68)$. Semua partisipan berasal dari fakultas yang berbeda dan berlatar belakang magister $(\mathrm{N}=3)$ serta doktoral $(\mathrm{N}=1)$. Jumlah partisipan yang relatif sedikit dalam studi ini dikarenakan keterbatasan waktu wawancara dosen saat pelatihan berlangsung.

Behavioral Belief. Bagian ini terdiri atas 3 topik utama yakni hal yang terlintas terkait food waste, keuntungan melakukan food waste dan kerugian melakukan food waste. Seorang partisipan bahkan menjelaskan food waste dengan kebiasaan yang sering ia temui. "Budaya buang makanan, sisa makanan, tidak menghabiskan makanan, memasak lalu membuang bahan makanannya, orang yang suka icip-icip tetapi tidak dihabiskan" (50 tahun, Perempuan, Sekolah Kajian Strategik dan Gender). Seluruh partisipan sepakat bahwa satu hal yang terlintas terkait food waste adalah sisa makanan. Selain itu, seluruh partisipan juga setuju bahwa perilaku food waste dapat menambah limbah. Dua partisipan mengakui bahwa seseorang yang membuang makanan kemungkinan karena faktor gizi dan lingkungan. "Makanan dipisahkan oleh petugas agar sisa makanan dapat diolah menjadi pupuk. Makanan yamg dibuang biasanya tinggi kolesterol". (28 tahun, Perempuan, Fakultas Kesehatan Masyarakat)

Normative Belief. Seluruh partisipan menyatakan bahwa rekan sejawat merupakan individu atau kelompok yang mampu mendorong sekaligus menghambat perilaku food waste. Hal tersebut mungkin saja terjadi karena peserta dari pelatihan adalah seluruhnya dosen. Selain itu, ada juga partisipan yang merasa bahwa orang yang 
paling berpengaruh bagi dirinya untuk tidak membuang makanan adalah orangtuanya.

Control Belief. Bagian ini terdiri atas 3 topik utama yakni faktor lain yang mendukung atau menghambat individu dalam melakukan perilaku food waste. Hasil menunjukan bahwa kondisi makanan diet, dan keyakinan agama menjadi faktor yang dianggap seluruh partisipan mampu mendorong mereka untuk membuang makanan. "Perilaku diet ketat bisa membuat seseorang tidak menghabiskan makanannya". (29 tahun, Laki-Laki, Fakultas IImu Administrasi). Selain itu, keyakinan agama merupakan faktor yang membuat seluruh partisipan dapat menghambat melakukan perilaku food waste. Partisipan juga mengaitkan food waste behavior dengan istilah mubazir atau dalam istilah agama islam sebagai perilaku yang menyia-nyiakan sesuatu. "Belief agama dimana perilaku mubazir adalah perilaku setan". (29 tahun, Perempuan, Fakultas Ekonomi dan Bisnis). Berdasarkan hasil wawancara diketahui simpulan pernyataan-pernyataan yang salient. Ketiga aspek yang sebelumnya digali dalam wawancara akan menjadi modal dalam membangun sebuah kuesioner yang sering digunakan dalam melihat gambaran model TPB. Aspek behavioral belief akan ditransformasikan ke dalam peran attitude, normative belief akan ditransformasikan ke dalam subjective norms, dan control belief akan ditransformasikan menjadi PBC.

\section{Studi 2}

Karakteristik Dosen. Partisipan dalam studi ini memiliki rentang usia antara 21 hingga 85 tahun $(M=39,40$ tahun, $S D=12,81)$. Partisipan didominasi oleh perempuan $(62 \%)$ dan memiliki latar belakang pendidikan magister (74\%). Status partisipan lebih banyak berasal dari kategori dosen tetap (76\%). Untuk memperoleh isu keterwakilan, kuesioner diisi oleh partisipan yang tersebar di 11 dari 15 fakultas di perguruan tinggi $\mathrm{XYZ}$.

Food Waste Behavior. Hasil analisis deskriptif secara keseluruhan menunjukan partisipan cenderung tidak setuju dengan perilaku food waste $(M=2,80 ; S D=1,017)$. Mean score pada pernyataan perilaku membawa makanan yang habis ketika di kantor diketahui sebesar 3,11 $(S D=1,435)$, mean score pada pernyataan perilaku tidak menawarkan makanan kepada teman saat memperoleh makanan yang tidak disukai diketahui sebesar 2,71 $(S D=1,380)$, mean score 2,60 $(S D=1,340)$ pada pernyataan perilaku tidak memisahkan makanan terlebih dahulu sebelum makan dan mean score 2,80 $(S D=1,017)$ pada variabel food waste behavior secara rerata (rentang jawaban 1 hingga 6). Analisis uji perbandingan pada faktor latar belakang pendidikan, jenis kelamin dan status dosen tidak menunjukan adanya perbandingan yang signifikan baik terhadap 3 pernyataan food waste behavior maupun skor rerata variabel food waste behavior itu sendiri $(\mathrm{p}>$ $0,05)$.

Atittude. Skor rerata secara keseluruhan menunjukan bahwa partisipan cenderung memiliki sikap yang tidak setuju terkait food waste behavior $(M=2,63 ; S D=0,714)$. Selain itu, partisipan cenderung agak setuju dengan sikap bahwa makanan yang terbuang dapat diolah menjadi pupuk organik $(M=4,47 ; S D=1,606$, rentang jawaban 1-6).

Partisipan dosen memiliki kecenderungan tidak setuju pada sikap yang menyatakan bahwa membuang makanan tidak akan berpengaruh pada masalah lingkungan $(M=1,92 ; S D=0,986$, rentang jawaban 1-6). Selain itu, partisipan dosen juga cenderung tidak setuju bahwa membuang makanan tidak akan berpengaruh pada kasus kelaparan di daerah lain $(M=1,53$; $S D=0,705$, rentang jawaban 1 sampai 6). Analisis uji perbandingan pada faktor latar belakang pendidikan, jenis kelamin dan status dosen tidak menunjukan adanya perbandingan yang signifikan baik terhadap 3 pernyataan atittude maupun skor rerata variabel atittude ( $p$ $>0,05$ ).

Subjective Norm. Skor rerata secara keseluruhan menunjukan bahwa partisipan cenderung memiliki norma subjektif yang tidak setuju terkait food waste behavior $(M=2,83$; $S D=0,833$ ). Selain itu, partisipan dosen cenderung tidak setuju terhadap teman sejawatnya yang menganggap bahwa membuang makanan adalah hal yang wajar $(M=2,66$; $S D=1,479$, rentang jawaban 1-6). Partisipan dosen juga cenderung tidak setuju terhadap anjuran orangtua mereka yang menganggap bahwa membuang makanan adalah hal yang wajar $(M=2,00 ; S D=1,143$, rentang jawaban 1-6).

Partisipan dosen juga cenderung agak setuju terhadap aturan perguruan tinggi yang menganjurkan untuk tidak menghasilkan sampah makanan $(M=3,83 ; S D=1,552$, rentang jawaban 1-6). Analisis uji perbandingan pada faktor latar belakang pendidikan, jenis kelamin dan status dosen tidak menunjukan adanya perbandingan yang signifikan baik terhadap 3 pernyataan subjective norm maupun skor rerata variabel subjective norm $(p>0,05)$. 
Tabel 1 Korelasi antar variabel

\begin{tabular}{lccccc}
\hline \multicolumn{1}{c}{ Variabel } & $M \pm S D$ & Attitude & $\begin{array}{c}\text { Subjective } \\
\text { norm }\end{array}$ & $\begin{array}{c}\text { Perceived } \\
\text { behavioral control }\end{array}$ & $\begin{array}{c}\text { Intention } \\
\text { Food } \\
\text { waste } \\
\text { behavior }\end{array}$ \\
\hline Attitude & $2,64 \pm 0,71$ & 1 & & & \\
\hline Subjective norm & $2,83 \pm 0,83$ & $0,25^{*}$ & 1 & 1 & 1 \\
\hline Perceived behavioral control & $2,60 \pm 0,90$ & $0,34^{* *}$ & $0,40^{* *}$ & $0,37^{* *}$ & $0,48^{* *}$ \\
\hline Intention & $2,16 \pm 0,83$ & $0,41^{* *}$ & $0,36^{* *}$ & $0,29^{* *}$ & 1 \\
\hline Food waste behavior & $2,80 \pm 1,02$ & $0,26^{* *}$ & $0,20^{*}$ & & \\
\hline
\end{tabular}

Keterangan: $M=$ Mean score; $S D=S t a n d a r d$ Deviation; $" p<0,05 ; " ~ p<0,01$

Perceived Behavioral Control. Skor rerata secara keseluruhan menunjukan bahwa partisipan cenderung memiliki kontrol perilaku yang tidak setuju terkait food waste behavior $(M=2,60 ; \quad S D=0,904)$. Selain itu, partisipan dosen cenderung agak tidak setuju bila keadaan diet merupakan faktor yang dapat menghambat mereka menghabiskan makananya $(M=2,66 ; \quad S D=1,349, \quad$ rentang jawaban 1-6).

Partisipan dosen juga cenderung agak tidak setuju bila mengetahui kandungan gizi sebelum makan dapat menjadi faktor yang dapat menghambat mereka menghabiskan makanannya $(M=3,01 ; \quad S D=1,336$, rentang jawaban 1-6). Partisipan dosen juga cenderung tidak setuju bila ajaran dalam agama dapat menjadi faktor yang dapat menghambat mereka menghabiskan makanannya $(M=2,12$; $S D=1,319$, rentang jawaban 1-6). Analisis uji perbandingan pada faktor latar belakang pendidikan, jenis kelamin dan status dosen tidak menunjukan adanya perbandingan yang signifikan baik terhadap 3 pernyataan PBC maupun skor rerata variabel PBC $(p>0,05)$.

Intention. Skor rerata secara keseluruhan menunjukan bahwa partisipan cenderung memiliki niat yang tidak setuju terkait food waste behavior $(M=2,16 ; S D=0,826)$. Secara spesifik, partisipan dosen cenderung tidak setuju jika di kemudian hari membuang makanan saat makan $(M=2,04 ; S D=1,049$; $M=2,28$, rentang jawaban 1-6) dan menyisakan makanan saat makan di luar rumah $(M=2,28$; $S D=1,19$, rentang jawaban 1-6). Analisis uji perbandingan pada faktor latar belakang pendidikan, jenis kelamin dan status dosen tidak menunjukan adanya perbandingan yang signifikan baik terhadap 2 pernyataan intention maupun skor rerata variabel intention $(p>$ $0,05)$.

Korelasi Antarvariabel. Tabel 1 menunjukkan gambaran skor semua variabel yang diuji beserta luaran analisis statistik korelasi antara variabel. Diketahui bahwa subjective norm memiliki mean score paling tinggi yakni 2,83 (rentang 1 hingga 6). Sementara itu, variabel intention memiliki mean score terendah yakni 2,16 (rentang 1 hingga 6). Selain itu, dalam luaran statistik tersebut, dapat dijelaskan bahwa terdapat korelasi positif yang signifikan antara variabel-variabel yang diuji. Korelasi tertinggi terjadi antara variabel intention dengan food waste behavior $(b=0,48 ; p<0,01)$.

Sementara itu, korelasi terendah ditunjukan oleh variabel subjective norm dengan food waste behavior $(b=0,19 ; p<0,05)$. Hasil ini juga menjadi landasan untuk peneliti dalam melakukan regresi berganda pada analisis selanjutnya.

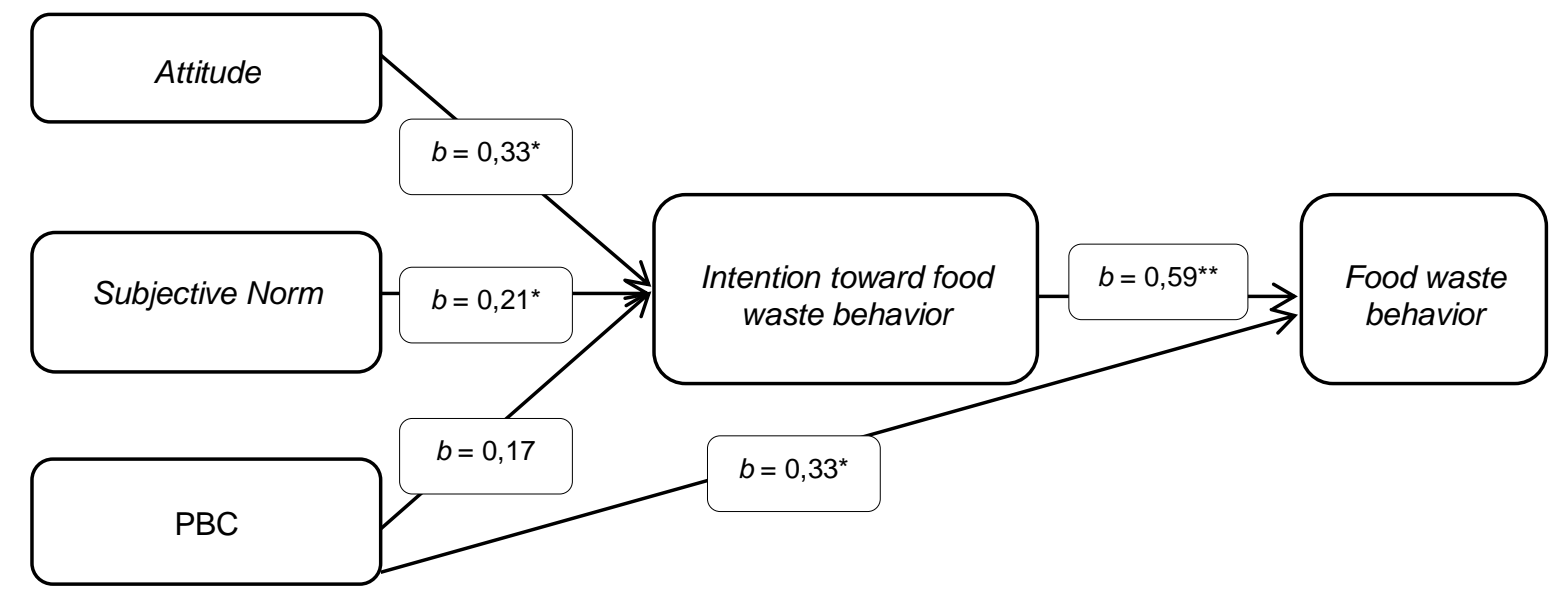

Keterangan: ${ }^{*} p<.05 ;{ }^{* *} p<.01 ; \mathrm{PBC}=$ perceived behavioral control

Gambar 1 Hasil analisis uji regresi variabel-variabel TPB 


\section{Faktor-Faktor yang memengaruhi Food Waste Behavior}

Hasil analisis seperti yang tersaji pada Gambar 1 menunjukan bahwa hanya variabel perceived behavioral control yang tidak secara signifikan memprediksi intention $(b=0,13 ; p=0,06)$. Hasil analisis regresi sederhana menunjukan, secara terpisah, baik perceived behavioral control maupun intention mampu memprediksi food waste behavior secara signifikan $(p<0,05)$. Temuan ini akan dijelaskan lebih lanjut dalam bagian pembahasan.

\section{PEMBAHASAN}

Hasil studi kualitatif menemukan belief dapat dijelaskan dalam beberapa temuan. Behavioral belief dosen menilai bahwa sampah makanan identik dengan perilaku membuang makanan. Selain itu, partisipan Studi 1 juga menganggap bahwa perilaku membuang makanan dapat ditoleransi jika diiringi dengan pengelolaan sampah organik yang benar, misalnya pembuatan pupuk. Temuan tersebut dapat bermakna negatif apabila di kemudian hari ditemukan lebih banyak individu yang sengaja dan tidak mengontrol pola makan karena alasan pengomposan. Hal tersebut sudah dibuktikan oleh studi Qi dan Roe (2017) yang menemukan bahwa informasi pengomposan sebagai konsekuensi munculnya sampah makanan justru akan meningkatkan perilaku individu dalam membuang makanan di kemudian hari. Meskipun demikian, behavioral belief semacam ini perlu dibuktikan dalam pengujian variabel atittude dengan pendekatan kuantitatif Studi 2.

Hasil pengujian studi kuantitatif pada variabel atittude menemukan sikap dosen bahwa sisa makanan dapat dikompos memang cukup tinggi. Hal ini dapat dikatakan mendukung temuan behavioral belief dosen pada Studi 1 secara kualitatif. Pemanfaatan sisa makanan untuk kompos memang tidak salah. Namun, dalam hirarki pengelolaan sampah makanan, pengomposan merupakan cara paling akhir yang harus dilakukan. Hal tersebut mengingat bahwa pengelolaan kompos dari sisa makanan pun menimbulkan bahaya bagi lingkungan (Kiswadayani et al., 2016). Selain itu, pengelolaan kompos di perguruan tinggi $X Y Z$ dinilai tidak maksimal karena lahan yang terbatas, membutuhkan waktu yang tidak sedikit dan potensi pencemaran lingkungan kampus (Mulya, 2018). Di sisi lain, temuan Studi 2 pada atittude menunjukan bahwa dosen cukup concern terhadap masalah lingkungan sebagai dampak dari adanya sisa makanan.
Untuk menjembatani fakta pengelolaan sampah makanan dan sikap individu, nampaknya diperlukan rancangan intervensi seperti edukasi yang dilakukan oleh studi Qi dan Roe (2017).

Studi kualitatif pada normative belief menyebutkan bahwa rekan sejawat sesama dosen merupakan kelompok yang dapat mendukung sekaligus menghambat perilaku food waste. Temuan studi kuantitatif juga mengonfirmasi bahwa teman lebih berpengaruh dibandingkan orangtua dalam praktik membuang makanan. Uniknya norma tambahan oleh peneliti yakni aturan kampus justru lebih kuat dibandingkan norma teman. Hasil tersebut dapat merefleksikan bahwa dosen kemungkinan akan lebih patuh untuk tidak menghasilkan sampah makanan ketika ada aturan kampus yang mengikat. Aturan kampus yang mengikat kemungkinan akan menjadi sebuah budaya yang disetujui bersama. Hal ini juga sejalan dengan studi yang menemukan bahwa budaya menjadi faktor eksternal yang turut memengaruhi individu dalam perilaku food waste (Bozzola et al., 2017). Sivitas akademika akan cenderung patuh pada aturan apalagi dalam konteks isu lingkungan. Studi oleh Lozano et al. (2013) merefleksikan bahwa sudah sepatutnya seluruh sivitas akademika diperkenalkan dengan budaya-budaya kampus yang berbasis pembangunan berkelanjutan.

Hasil studi kualitatif pada control belief menemukan faktor kondisi diet dan makanan dengan gizi berlebih merupakan pendorong utama dosen menyisakan makananya kemudian membuangnya. Sebaliknya, faktor utama yang menghambat dosen untuk tidak membuang makanannya yakni keyakinan agamanya. Hasil studi kuantitatif mengonfirmasi bahwa makanan dengan gizi berlebih yang paling potensial mendorong perilaku food waste. Temuan ini dapat merefleksikan bahwa dosen memiliki pengetahuan yang cukup tinggi terutama terkait kandungan gizi sebuah makanan. Hal tersebut didukung oleh studi yang menunjukan bahwa pengetahuan berperan penting dalam konteks perilaku food waste individu (Gupta, 2016). Tampilan makanan kemungkinan dapat menunjukan kandungan gizi sebuah makanan. Hal tersebut dapat juga berpotensi mendorong individu dalam mengevaluasi makanannya dan berakhir pada keputusan membuang makanannya atau tidak (Iftitah, Sari, Sari \& Waryana, 2017)

Berdasarkan hasil studi kuantitatif, dapat disimpulkan bahwa $\mathrm{H} 1$ ditolak, tetapi $\mathrm{H} 2$ dan H3 diterima. Hipotesis 1 ditolak karena PBC 
tidak mampu memprediksi intensi secara signifikan. Temuan dalam hipotesis 1 tidak sejalan dengan studi sebelumnya (Mamahit et al., 2019; Sofiani \& Saefuloh, 2019) yang menemukan bahwa PBC sangat signifikan memprediksi intensi. Selain itu, temuan hipotesis 2 dan 3 sejalan dengan studi sebelumnya oleh Afifah dan Djuwita (2019). PBC dinilai mampu secara langsung memengaruhi perilaku tanpa adanya peran intensi. Hal juga mendukung postulat utama Ajzen (2005) dalam menjelaskan kerangka TPB. Seluruh temuan ini menarik jika ditinjau berdasarkan hasil studi kualitatif sebagai landasan dalam membangun pernyataan yang salient di Studi 2 ini.

Merujuk pada studi kualitatif, PBC dibentuk oleh adanya antensenden control belief. Studi kualitatif menemukan bahwa control belief dosen dalam membuang makanan adalah kondisi diet, kandungan gizi makanan dan keyakinan agama. Oleh karenanya, merujuk pada temuan pengujian hipotesis 2 dalam Studi 2 , peneliti menduga kemungkinan terdapat faktor lain yang turut berkontribusi sebagai control belief dosen dalam membuang makanan. Studi oleh Russell et al. (2017) misalnya menemukan bahwa faktor emosi dan kebiasaan menjadi prediktor penting terhadap perilaku food waste. Kebiasaan merupakan respon otomatis yang terafiliasi dengan perilaku masa lalu yang terjadi berulang (Best \& Papies, 2017). Perilaku food waste tanpa disadari terjadi tanpa melewati mekanisme psikologis yang kompleks. Lebih spesifik, kebiasaan sebagai faktor penting dalam perilaku prolingkungan lain di kampus pun juga telah dibuktikan oleh studi Afifah dan Djuwita (2019).

Peran intensi dalam kerangka TPB pada studi ini juga masih membuktikan eksistensinya. Hal tersebut didukung oleh hasil analisis regresi pada hipotesis 3 dan analisis korelasi sebelumnya. Analisis korelasi pada studi kuantitatif telah menunjukan intensi memiliki korelasi yang paling tinggi dengan food waste behavior dibandingkan variabel lainnya. Temuan ini secara langsung mendukung studi sebelumnya (Afifah \& Djuwita, 2019; Agar, 2018; Volva \& Djamaludin, 2018). Kerangka TPB memang memiliki postulat yang kuat bahwa niat merupakan cerminan dari sebuah perilaku akan terjadi. Di sisi lain, peneliti mengkritik bahwa terdapat lemahnya bukti perubahan perilaku dari adanya niat (Sniehotta, Presseau, \& Araújo-Soares, 2014). Studi oleh Best dan Papies (2017) menemukan kebiasaan merupakan salah satu faktor kuat yang muncul di antara niat dan perilaku individu. Menanggapi kritik tersebut, Ajzen (2015b) terbuka terhadap perluasan teorinya. Ajzen dengan bijaksana menyadari bahwa munculnya hasil studi dari lemahnya hubungan niat dan perilaku adalah limitasi dari TPB itu sendiri.

\section{SIMPULAN DAN SARAN}

Hasil analisis tematik Studi 1 menunjukan bahwa behavioral belief dosen terkait food waste berkaitan dengan makanan sisa yang akhirnya terbuang dan menjadi sampah. Dosen memiliki belief bahwa makanan yang terbuang dapat diolah kembali menjadi pupuk bagi kampus. Hasil tersebut juga cukup terkonfirmasi oleh hasil Studi 2 yang menemukan sikap dosen bahwa sisa makanan dapat dikompos memang cukup tinggi. Selain itu, ditemukan juga bahwa rekan sejawat menjadi normative belief dosen paling salient dalam perilaku. Uniknya, hasil Studi 2 terkait subjective norm menemukan bahwa norma teman tidak begitu cukup kuat dibandingkan norma aturan kampus mengenai perilaku food waste. Selain itu, diketahui bahwa control belief dosen yang sangat menonjol terkait perilaku food waste adalah kondisi diet, kandungan gizi, dan keyakinan agama. Temuan tersebut juga didukung oleh studi kuantitatif PBC yang menghasilkan kandungan gizi memiliki skor yang cukup tinggi dibandingkan keadan diet dan keyakinan agama. Secara keseluruhan pada Studi 2 ditemukan bahwa hanya atitude dan subjective norm yang mampu memprediksi intensi secara signifikan ( $\mathrm{H} 1$ ditolak). Adapun PBC dan intensi secara signifikan mampu memprediksi perilaku food waste dalam analisis regresi secara terpisah ( $\mathrm{H} 2$ \& $\mathrm{H} 3$ diterima).

Studi ini tidak terlepas dari adanya keterbatasan. Pertama, peneliti hanya fokus dalam menguji faktor-faktor yang ada dalam kerangka TPB. Studi selanjutnya dapat menguji faktor lain yang diduga turut berkorelasi dengan perilaku food waste. Kedua, peneliti mengukur perilaku food waste menggunakan self-report. Pengukuran perilaku food waste memang beragam, seperti penimbangan secara langsung. Namun, studi selanjutnya dapat melihat kondisi partisipan, setting, dan juga faktor lainnya untuk dapat memilih pengukuran perilaku lain yang lebih robust.

Hasil studi ini akan sangat berguna bagi peneliti selanjutnya dalam merancang sebuah intervensi yang dapat menurunkan perilaku food waste pada dosen di perguruan tinggi. Selain itu, dosen juga dinilai sebagai subjek atau target yang memiliki peran penting di perguruan tinggi. Dosen juga seringkali memiliki 
jabatan fungsional di perguruan tinggi yang mampu memengaruhi kebijakan mulai di level departemen hingga perguruan tinggi. Oleh karena itu, hasil studi ini atau studi intervensi selanjutnya dapat menjadi cara baru bagi perguruan tinggi dalam mewujudkan green campus melalui inovasi berbasis lingkungan.

\section{DAFTAR PUSTAKA}

[BPS] Badan Pusat Statistik. (2018). Garis kemiskinan makanan berdasarkan provinsi. Jakarta, ID: BPS

[EIU] Economist Intelligence Unit. (2018). Whitepaper: Food Sustainability Index. Retrieved from http://foodsustainability.eiu .com/whitepaper/

[FAO] Food and Agriculture Organization. (2013). Food wastage footprint: Impacts on natural resources (Summary Report). Retrieved from https://fao.org/news

Afifah, A. N., \& Djuwita, R. (2019). Alah bisa karena biasa: Peran perceived behavioral control dalam perilaku memilah sampah di kalangan penjual kantin universitas XYZ. Jurnal psikologi sosial, 17(2), 125139. doi:10.7454/jps.2019.16

Agar, A. D. (2018). Mandatory motherhood and compulsory careers: An application of theory of planned behaviour to young women's mothering and career intentions (Dissertation). Saskatoon, CA: University of Saskatchewan

Ajzen I. (2005). Attitudes, personality, and behavior (2nd ed.). Maidenhead, UK: Open University Press.

Ajzen, I. (2015). Consumer attitudes and behavior: The theory of planned behavior applied to food consumption decisions. Italian Review of Agricultural Economics, 70(2), 121-138. doi:10.13128/REA-18003

Ajzen, I. (2015). The theory of planned behaviour is alive and well, and not ready to retire: A commentary on Sniehotta, Presseau, and Araújo-Soares. Health Psychology Review, 9(2), 131-137. doi:10.1080/17437199.2014.883474

Aschemann-Witzel, J., De Hooge, I., Amani, P., Bech-Larsen, T., \& Oostindjer, M. (2015). Consumer-related food waste: Causes and potential for action. Sustainability, 7(6), 6457-6477. doi:10.3390/su7066457

Best, M., \& Papies, E. K. (2017). Right here, right now: Situated interventions to change consumer habits. Journal of the
Association for Consumer Research, 2(3), 333-358. doi:10.1086/695443

Bozzola, M., Dal Palù, D., \& De Giorgi, C. (2017). Design for leftovers: From food waste to social responsibility. The Design Journal, 20(1), 1692-1704. doi:10.1080/14606925.2017.1352692

Carr, A., Shin, Y. H., Severt, K., \& Lewis, M. (2017). A qualitative approach to understanding the underlying beliefs of microbrewery consumers. International Journal of Hospitality Beverage Management, 1(1), $4 . \quad$ doi:10.34051 /j/2019.4

Cresswell, J. W. (2007). Qualitative inquiry and research design: Choosing among five approaches (2nd edition). California, CA: Sage Publication. doi:10.1111/14679299.00177

Egolf, A., Siegrist, M., \& Hartmann, C. (2018). How people's food disgust sensitivity shapes their eating and food behaviour. Appetite, 127(2), 28-36. doi:10.1016/ j.appet.2018.04.014

Fadhilah, N., \& Yudihanto, G. (2013). Pemanfaatan sampah makanan menjadi bahan bakar alternatif dengan metode biodrying. Jurnal Teknik ITS, 2(2), B290B293. doi:10.12962/j23373539.v2i2.4962

Faul, F., Erdfelder, E., Lang, A.-G. \& Buchner, A. (2007). G-power 3: A flexible statistical power analysis program for the social, behavioral, and biomedical sciences. Behavior Research Methods, 39(2), 175191. doi:10.3758/BF03193146

Fishbein, M., \& Ajzen, I. (2010). Predicting and changing behavior: The reasoned action approach. New York, US: Psychology Press

Graham-Rowe, E., Jessop, D. C., \& Sparks, P. (2015). Predicting household food waste reduction using an extended theory of planned behaviour. Resources, Conservation and Recycling, 101(2), 194202. doi:10.1016/j.resconrec.2015.05.020

Greenmetric. (2019). Participants 2018 (Web Resmi UI Green Metric). Retrieved from http://greenmetric.ui.ac.id/

Guinee, J. (2018). LCA and LCSA: How can they contribute to the global sustainable development goals (SDGs)?. Dipresentasikan dri 3rd International Conference Series on Life Cycle Assessment (ICSoLCA) on "LCA as a 
metric to achieve SDGs", The National Library of Republic Indonesia, Jakarta.

Gupta, D. (2016). The persuasive effect of youtube videos on food waste habits (Theses). San Fransisco, US: University of San Fransisco

Iftitah, F., Sari, T., Sari, T., \& Waryana, W. (2017). Hubungan kondisi psikologis dan penampilan makanan dengan sisa makanan pasien rawat inap di RSUD Panembahan Senopati Bantul (Dissertation). Yogyakarta, ID: Poltekkes Kemenkes Yogyakarta.

Kariyasa, K., \& Suryana, A., (2016). Memperkuat ketahanan pangan melalui pengurangan pemborosan pangan. Analisis Kebijakan Pertanian, 10(3), 269288. doi:10.21082/akp.v10n3.2012.269288

Kiswadayani, A. V., Susanawati, L. D., \& Wirosoedarmo, R. (2016). Komposisi sampah dan potensi emisi gas rumah kaca pada pengelolaan sampah domestik: Studi Kasus TPA Winongo Kota Madiun. Jurnal Sumber Daya Alam dan Lingkungan, 2(3), 9-17.

Lozano, R., Lozano, F. J., Mulder, K., Huisingh, D., \& Waas, T. (2013). Advancing higher education for sustainable development: International insights and critical reflections. Journal of Cleaner Production, $48(2), \quad 3-9 . \quad$ doi:10.1016/j.jclepro .2013 .03 .034

Mak, T. M., Iris, K. M., Tsang, D. C., Hsu, S. C., \& Poon, C. S. (2018). Promoting food waste recycling in the commercial and industrial sector by extending the Theory of Planned Behaviour: A Hong Kong case study. Journal of Cleaner Production, 204(2018), 1034-1043. doi:10.1016/ j.jclepro.2018.09.049

Mamahit, M. V., Kalangi, J. B., \& Pandowo, M. $\mathrm{H}$. (2019). Analyzing the purchase intention of tumbler by millennial generation in Manado. Jurnal EMBA: Jurnal Riset Ekonomi, Manajemen, Bisnis dan Akuntansi, 7(3), 3289-3298. doi:10.35794/emba.v7i3.24213

Mondéjar-Jiménez, J. A., Ferrari, G., Secondi, L., \& Principato, L. (2016). From the table to waste: An exploratory study on behaviour towards food waste of Spanish and Italian youths. Journal of Cleaner Production, 138(2016), 8-18. doi:10.1016/ j.jclepro.2016.06.018
Mulya. (2018). Sampah organik di Universitas Indonesia. Depok, ID: Personal communication

Painter, K., Thondhlana, G., \& Kua, H. W. (2016). Food waste generation and potential interventions at Rhodes University, South Africa. Waste Management, 56(2016), 491-497. doi:10.1016/j.wasman.2016.07.013

Porpino, G., Wansink, B., \& Parente, J. (2016). Wasted positive intentions: The role of affection and abundance on household food waste. Journal of food products marketing, 22(7), 733-751. doi:10.1080/ 10454446.2015.1121433

Prasetyo, D. T. (2019). Faktor apa saja yang mempengaruhi seseorang berperilaku food waste di pesta pernikahan?. Jurnal Kesejahteraan Keluarga dan Pendidikan, 6(02), 87-92. doi:10.21009/JKKP.062.02

Qi, D., \& Roe, B. E. (2017). Foodservice composting crowds out consumer food waste reduction behavior in a dining experiment. American Journal of Agricultural Economics, 99(5), 1159-1171. doi:10.1093/ajae/aax050

Russell, S. V., Young, C. W., Unsworth, K. L., \& Robinson, C. (2017). Bringing habits and emotions into food waste behaviour. Resources, Conservation and Recycling, 125(2017), 107-114. doi:10.1016/ j.resconrec.2017.06.007

Shin, Y. H., Im, J., \& Severt, K. (2020). Qualitative assessment of key beliefs in regards to consumers' food truck visits. Journal of Quality Assurance in Hospitality \& Tourism, 21(2), 129-145. doi:10.1080/1528008X.2019.1627271

Sniehotta, F. F., Presseau, J., \& Araújo-Soares, V. (2014). Time to retire the theory of planned behaviour. Health Psychology Review, 8(1), 1-7. doi:1080/17437199 .2013.869710

Sofiani, S. S., \& Saefuloh, D. (2019). Penggerak niat perilaku pembelian produk fesyen ramah lingkungan dengan teori perilaku yang direncanakan. In Prosiding Industrial Research Workshop and National Seminar, 10(1), 767-776). doi:10.35313/irwns.v10i1.1516

Tiwi. (2018). Penimbangan sampah makanan di pelatihan dosen Universitas Indonesia. Depok, ID: Personal Communication 
Volva, L., \& Djamaludin, D. (2018). Perilaku penggunaan tas belanja pada ibu rumah tangga tidak bekerja dalam perspektif theory of planned behavior. Jurnal IImu Keluarga \& Konsumen, 11(1), 49-59. doi:10.24156/jikk.2018.11.1.49

Whitehair, K. J., Shanklin, C. W., \& Brannon, L. A. (2013). Written messages improve edible food waste behaviors in a university dining facility. Journal of the Academy of Nutrition and Dietetics, 113(1), 63-69. doi:10.1016/j.jand.2012.09.015

Willig, C. (2008). Introducing qualitative research in psychology (2nd Edition). Glasgow, UK: Mc Graw Hill 